\title{
LA EXCLUSIÓN ÉTNICA EN LA EDUCACIÓN BÁSICA Y SECUNDARIA EN LA NACIENTE REPÚBLICA DE COLOMBIA, 1819-1825
}

\author{
Roger Pita Pico* \\ Academia Colombiana de Historia \\ Línea de investigación: Educación, cultura y nación en Colombia \\ rogpitc@hotmail.com
}

\begin{abstract}
RESUMEN
El propósito de este artículo consiste en analizar las dificultades del naciente Estado republicano para diseñar un sistema educativo incluyente que cobijara a las minorías étnicas. Muy poco se logró avanzar en estos años por superar la mentalidad segregacionista y la rígida estructura social que habían primado durante el periodo de dominio hispánico. Así, entonces, los principios republicanos de igualdad y libertad no se vieron reflejados en la política educativa, que resultó afectada por la crisis económica, el déficit fiscal y los estragos causados por las guerras de Independencia; por consiguiente, a los indios y a los negros se les aplazó el ejercicio pleno de sus derechos como ciudadanos, con lo cual se limitaron sus oportunidades de reconocimiento y ascenso socio-económico.
\end{abstract}

Palabras claves: indígenas, negros, minorías étnicas, educación básica, enseñanza secundaria, República, Colombia.

* Academia Colombiana de Historia; Línea de investigación: Educación, cultura y nación en Colombia; e-mail: rogpitc@hotmail.com 


\title{
ETHNIC EXCLUSION IN BASIC AND SECONDARY EDUCATION IN THE BEGINNING OF THE REPUBLIC OF COLOMBIA, 1819-1825
}

\begin{abstract}
The purpose of this article is to analyze the difficulties of the beginning of the republican state to design an inclusive education system that would cover ethnic minorities. Very little progress was made in these years to overcome the segregationist mentality and the rigid social structure that had prevailed during the Hispanic domain. So, then, the republican principles of equality and freedom were not reflected in educational policies, which were affected by the economic crisis, the fiscal deficit and the devastation caused by the wars of independence. Therefore the civil rights of Indians and blacks were postponed, thus their chances of recognition and socio-economic improvement were limited.
\end{abstract}

Key words: indigenous, blacks, ethnic minorities, primary education, secondary education, Republic, Colombia.

\section{A EXCLUSÃO ÉTNICO NA EDUCAÇÃO BÁSICA E SECUNDÁRIA NA REPÚBLICA NASCENTE DA COLÔMBIA, 1819-1825}

\begin{abstract}
RESUMO
O objetivo deste artigo é analizar as dificuldades do nascente Estado republicano para projetar um Sistema educacional inclusivo para abranger às minorias étnicas. Muito pouco progresso foi alcançado nos ultimos anos para superar a mentalidade segregacionista e a estrutura social rígida que prevaleceu durante o período de domínio hispânico. Assim, então, os princípios republicanos de igualdade e liberdade não se refletiram na política educacional, que resultou afetada pela la crise econômica, o déficit fiscal e da devastação causadas pelas guerras de Independência; portanto, aos índios e aos negros foram adiadas para exercer plenamente os seus direitos como cidadaõs, assim suas chances de reconhecimento e avanço sócio-econômico foram limitados.
\end{abstract}

Palavras chaves: indígenas, negros, minorias étnicas, ensino básico, ensino secundario, República, Colômbia. 


\section{INTRODUCCIÓN}

Desde sus inicios, y durante mucho tiempo, la historiografía nacional se dedicó fundamentalmente a elaborar una historia que sólo aludía a pequeños grupos dominantes, pero dejaba por fuera a una multiplicidad de actores sociales que yacían prácticamente invisibles; se desconocía o se subvaloraba a esas comunidades anónimas, a las que sólo se retrotraía bajo los apelativos de "pueblo" o "gente", por no mencionar los más peyorativos.

A mediados de la década de los 80 del siglo pasado, surgieron, en la India, los estudios sobre grupos subalternos, que buscaban registrar la existencia de aquellas personas del común, que se encontraban bajo el control de grupos dominantes. Dentro de los primeros autores, puede citarse a Ranajit Guha. En Latinoamérica, este tema lo han desarrollado Florencia Malon y James Sanders, al referirse a casos concretos ocurridos en México, Perú y Colombia ${ }^{1}$.

Por esos años, en el país también surgió el interés por la historia social con una óptica más incluyente; encuadrado en esta tendencia, adquirió especial auge el estudio de los indios y los negros ${ }^{2}$. El objetivo propuesto apuntaba, entonces, a superar la marginalidad a que también se había sometido a estas comunidades étnicas en nuestra historia, con lo que ha empezado a llenarse un vacío histórico sobre un asunto que generalmente se pensaba no revestía una trascendencia tal que ameritara abordar su estudio.

En los años recientes, y con motivo de la celebración del Bicentenario de la Independencia de Colombia, se ha registrado un interés por adelantar investigaciones que permitan construir una mirada más integral sobre la impronta dejada por los grupos sociales en el periodo independentista y en los primeros años de vida republicana. El propósito, entonces, ha sido no sólo auscultar la dimensión política, militar y económica de estos actores sociales, sino, también, su universo relacional y su desarrollo social, educativo y cultural.

Por la misma disponibilidad de fuentes, buena parte de los estudios sobre la Historia de la educación en Colombia ha enfocado su atención en aquellos sectores sociales que, por sus capacidades económicas, tuvieron más acceso a las aulas de clase, es decir, los blancos y mestizos, lo que significa que los indios y los negros, en su calidad de grupos étnicos minoritarios, quedaban prácticamente

1. Para ampliar más este tema, véase: Juan Ignacio Arboleda Niño. Entre la libertady la sumisión. Estrategias de liberación de los esclavos en la gobernación de Popayán durante la Independencia, 1808-1830 (Bogotá: Departamento de Historia de la Universidad de los Andes, 2006; Documento CESO No. 110), 7-8.

2. Jaime Jaramillo Uribe. Ensayos de Historia Social (Bogotá: Tercer Mundo/Ediciones Uniandes, 1989), tomo II, 203-224. 
por fuera de esos análisis debido a los escasos niveles de cobertura. Sobre estos segmentos de la sociedad apenas es posible encontrar alusiones muy cortas y tangenciales.

Las investigaciones sobre las comunidades indígenas y negras se inscriben también dentro del ámbito de la corriente de la Historia social de la educación, que acentúa en los verdaderos sujetos de la historia, frente a la postura tradicional de la Historia enfocada en personalidades, una tendencia que propicia el diálogo interdisciplinario con otras ciencias, como la antropología, la sociología y la Historia de las mentalidades, entre otras. A los temas tradicionales de las ideas pedagógicas, las instituciones y las políticas educativas, la nueva historiografía social ha planteado nuevas temáticas, como la historia de la infancia, la historia de la educación de la mujer, la incorporación de los sectores sociales marginados y las minorías. Esta corriente se reviste de un mayor compromiso por cuanto apunta a sustituir la tradicional historia narrativa, por una historia problema que permite una mayor reflexión con la cultura de su época y ofrece, además, elementos claves para comprender el presente y tratar de dilucidar el futuro ${ }^{3}$.

En respuesta a los vacíos existentes y en el marco de las corrientes historiográficas referidas, este artículo pretende examinar las dificultades y complicaciones, del naciente Estado republicano en Colombia, para extender los beneficios de la educación elemental y secundaria a los indios y a los negros.

La metodología para llevar a cabo este trabajo de investigación implicó un estudio descriptivo y cualitativo a partir de la consulta e interpretación de fuentes primarias de archivo, informes de gobierno, acervos normativos y la revisión detallada de los periódicos de la época, todo esto complementado con el análisis de fuentes secundarias alusivas al tema. El examen comparativo también se presenta en este artículo en el momento de considerar las rupturas y continuidades registradas en el periodo de transición de la Colonia a la República y el paso por el álgido periodo de la lucha independentista.

Durante el periodo de dominio hispánico, las escuelas eran anexas a los colegios o a los conventos, pero eran pocas las de carácter público; el número de colegios era, en realidad, muy reducido, siendo sus principales promotores los jesuitas. De hecho, muy poca atención le brindó el gobierno español a estos sectores básicos de la educación ${ }^{4}$.

3. Virginia Guichot Reina. Historia de la educación: reflexiones sobre su objeto, ubicación epistemológica, devenir histórico y tendencias actuales. En: Revista Latinoamericana de Estudios Educativos, Vol. 2, No. 1 (enero-junio 2006), 38-40.

4. Bárbara Yadira García Sánchez. De la educación doméstica a la educación pública en Colombia. Transiciones de la Colonia a la República (Bogotá: Universidad Distrital Francisco José de Caldas, 2007), 50. 
Con la llegada del movimiento de la Ilustración, en el siglo XVIII, se buscó una mayor promoción de las ciencias útiles y un mayor control y uniformidad en los contenidos y Planes de estudio; era esta una reforma secularizante y con claras intenciones de acentuar la intervención estatal ${ }^{5}$.

Imbuido por las ideas liberales, que empezaban a tomar auge a principios del siglo XIX, el intelectual criollo Francisco José de Caldas había planteado, en 1808 , la necesidad de formar una escuela a la que todos pudieran acceder, sin distinción de clase ${ }^{6}$.

El periodo de Independencia, iniciado en 1810 con los primeros movimientos de autonomía política y extendido por espacio de una década, significó una etapa de estancamiento en el lento desarrollo que venía experimentando la educación básica y secundaria. La crisis económica y la tensión política fueron dos de las principales secuelas de este lapso de confrontación militar con los españoles.

En 1819, luego de alcanzada la victoria militar en la batalla de Boyacá, los patriotas emprendieron el proceso de fijar las bases de una nación libre y soberana sustentada en los principios republicanos, un propósito que sólo pudo consolidarse al cabo de tres años con la expulsión definitiva a los españoles de las provincias de la Costa Caribe y del Sur; eran tiempos en los que se hacían ingentes esfuerzos para moldear una estructura burocrática y administrativa con miras a cristalizar la gran cantidad de planes y proyectos educativos concebidos como propulsores del progreso y la felicidad de la nación en ciernes.

El problema consistió en que el cambio de gobierno fraguado en 1819 no implicó automáticamente una transformación sustancial en la mentalidad de los ciudadanos y, por eso, muchos sectores aún defendían la estructura anquilosada del antiguo régimen de dominación colonial, con todas sus inequidades y segregaciones, producto de la rígida estructura social. Así, entonces, el género, la raza y la condición socio-económica seguían siendo factores evidentes de exclusión en materia educativa.

Adversas eran las condiciones sociales y económicas en que estaban inmersos los indios y los negros; históricamente, habían desempeñado oficios "viles o bajos", que implicaban arduas jornadas de servicio a sus patronos o amos; niños y jóvenes de estos sectores populares solían entrar al mundo laboral desde temprana edad, en general a actividades menores y tareas domésticas ${ }^{7}$. No se debe olvidar que esta época, en la que se cimentaba la República, eran evidentes

5. Luis Antonio Calderón Rodríguez. La Ilustración francesa y su influencia ideológica en Colombia (Manizales: Universidad de Caldas, 2001), 53-55.

6. Francisco José de Caldas. Estudios varios (Bogotá: Ministerio de Educación Nacional, 1941), 78.

7. Patricia Londoño Vega y Santiago Londoño Vélez. Los niños que fuimos. Huellas de la infancia en Colombia (Bogotá: Banco de la República, 2012), 19, 23. 
los estragos de la dura crisis económica derivada del frenesí de la guerra, una situación que afligió al conjunto de la sociedad, pero que, es probable, pudo ser más notoria para aquellos dos grupos étnicos, en razón a su postrera posición en la escala social; eran tiempos de generalizada escasez, que pudo significar intensos sacrificios y esfuerzos solidarios de supervivencia a nivel familiar y comunal. El descenso demográfico ${ }^{8}$, las fugas, los destierros, la fragmentación familiar, las epidemias, el maltrato y la desnutrición, fueron factores comunes que aquejaron a ambas etnias; así, entonces, con esta realidad se hacía difícil y desalentador para los padres enviar a sus pequeños a las aulas.

\section{1. “CIVILIZAR" A LOS INDÍGENAS}

En el marco de las exploraciones pioneras a territorio neogranadino, al blanco se lo tipificó indefectiblemente como conquistador-dominador, mientras que al indio se lo rotuló como conquistado y vencido. Estas connotaciones, derivadas del teatro de las guerras de Conquista, configuraron, desde un principio, el status para cada uno dentro de una estructura jerárquica bien delimitada, que se complementaba con sus respectivas especificidades culturales.

La élite blanca reafirmó su posición de dominio social y racial; para el español, las diferencias que lo distanciaban del indígena no eran meramente fenotípicas, sino también había carácter y comportamientos intrínsecos a cada grupo. De acuerdo con el pensamiento de la época, existía una compaginación entre raza y conducta, de manera que cada persona transmitía por herencia las cualidades o defectos inherentes a su color de piel ${ }^{9}$.

Aun cuando, en teoría, la Corona les había otorgado a los indios igualdad civil y política, tal como a los vasallos españoles, de todos modos recayó sobre ellos una imagen peyorativa, producto de su posición como raza vencida y postrada culturalmente. La mayoría de escritos coloniales se refería a ellos con descalificaciones de todo orden; se los vio con una actitud despreciativa, degradante y compasiva; se creía que aquel exponente aborigen era, por lo general, poseedor de no pocos vicios innatos, al tildárselo sistemáticamente de ladrón, miserable e ingenuo.

Aun con el paso de las décadas, los españoles y criollos mantenían entrañada una mentalidad de casta; en la Instrucción que redactó hacia 1809 el cabildo del

8. En el censo de 1778 , los indígenas representaban el $20 \%$ del total de la población de la Nueva Granada, mientras que los esclavos escasamente llegaban al 8\%. Hacia 1810, al inicio de las guerras de Independencia, era ya evidente el declive demográfico de estas dos etnias, al mismo tiempo que se consolidaba la mayoría conformada por blancos y mestizos. Hermes Tovar Pinzón. Convocatoria al poder del Número (Bogotá: Archivo General de la Nación, 1994), 86-88.

9. Virginia Gutiérrez de Pineda y Roberto Pineda Giraldo. Miscegenación y cultura en la Colombia colonial 1750-1810 (Bogotá: Ediciones Uniandes, 1999), tomo I, 280-281. 
Socorro, para el diputado del Nuevo Reino de Granada ante la Junta Suprema de España e Indias, se hizo una desalentadora descripción sobre los habitantes naturales de estas latitudes: "[...] estos por lo común viven en comunidad y a son de campana, son estúpidos y tan pobres que parece no extienden sus ideas más allá del momento presente"10.

Esta percepción peyorativa y segregacionista se extendía a todos los ámbitos, incluso al educativo; en 1789, el cura de Girón, don Felipe Salgar, le reiteró al gobierno virreinal la necesidad de establecer una escuela de primeras letras, para lo cual presentó un Reglamento, cuyos numerales 9o, $10^{\circ}$ y $11^{\circ}$ - fijaron una serie de recomendaciones concernientes a la segregación étnica en el aula de clase; en vista de la imposibilidad de contar con un edificio público suficientemente amplio, se propuso adecuar en la sala más grande de la casa del maestro una división:

[...] que consistirá en separar los bancos o escaños de la testera superior, de los de la inferior, dejando entre unos y otros una o media vara de intermedio. Servirá esto para denotar que los niños nobles ocupan las bancas de arriba y los plebeyos y gentes de castas ${ }^{11}$ los de abajo. División que se conceptúa suficiente para que los unos no se mezclen con los otros y se guarden recíprocamente los respetos que son debidos a cada clase ${ }^{12}$.

Se hizo un llamado a los párvulos de "buena estirpe" para que no injuriaran con mofas o malas palabras a los de baja extracción, ni tampoco se mezclaran con ellos, sino únicamente en el momento de enseñarles o auxiliarlos "por efecto de la generosidad que debe ser propia de la gente noble". De este modo, los niños blancos se acostumbrarían "a mirar bajo la perspectiva que conviene a los otros hombres de clase inferior"13.

En la Conquista y la Colonia, la instrucción de los niños y los jóvenes indígenas fue muy escasa y se enfocó básicamente en la gramática y en la disciplina religiosa, dirigida a extirpar la idolatría ${ }^{14}$. En junio de 1778, el visitador Francisco Antonio Moreno y Escandón planteó la necesidad de abrir una escuela pública primaria, en el pueblo indígena de Nemocón, con cargo a las rentas de las salinas de esta localidad ${ }^{\mathbf{1 5}}$; este alto funcionario del gobierno virreinal había tenido ya cierto protagonismo en temas educativos y culturales, como la apertura de una

10. Horacio Rodríguez Plata. La antigua provincia de Socorro y la Independencia (Bogotá: Biblioteca de Historia Nacional, 1963), Vol. XCVIII, 41.

11. Cuando se hablaba de castas, se hacía referencia a los indios, los negros y los mestizos.

12. Guillermo Hernández de Alba (comp.). Documentos para la historia de la educación en Colombia (Bogotá: Editorial Kelly, 1983), tomo V, 175.

13. Hernández de Alba (comp.), Documentos para la historia de la educación en Colombia.

14. Londoño Vega y Londoño Vélez, Los niños que fuimos, 23.

15. Escuela en Nemocón para enseñanza de primeras letras (Nemocón, 1778), en: Archivo General de la Nación (AGN), Sección Archivo Anexo, Fondo Instrucción Pública, tomo 2, f. 196r. 
biblioteca pública en Santafé y el diseño de un Plan de estudios ${ }^{16}$; su concepción se insertaba en la Reforma educativa inspirada en la Ilustración, con la que se pretendía reemplazar el escolasticismo por el aprendizaje de las matemáticas y las ciencias naturales, todo con miras a promover el estudio de disciplinas fructíferas para el progreso económico; era un deseo de los Ilustrados ver multiplicadas las escuelas, para formar ciudadanos útiles y virtuosos, regidos con los criterios de una educación uniforme y controlada por el Estado ${ }^{17}$. En su recorrido, Moreno y Escandón pudo palpar el descuido y la falta de atención en el nivel de educación primaria.

En el período de Independencia, se ampliaron las posibilidades de desarrollo educativo para la niñez y la juventud indígena. En concordancia con la igualación de derechos proclamada por los principios republicanos, el segundo punto esgrimido por la Junta Suprema de Santafé, constituida en julio de 1810, en los albores de la Primera República Federativa, dio vía libre para que a los indígenas se les distribuyeran en propiedad las tierras de resguardo, según su justo valor y de acuerdo a la cantidad de integrantes de cada familia. El numeral $4^{\circ}$ ordenó separar, de la totalidad de estos terrenos, un área proporcionada para el establecimiento y dotación de una escuela pública para la instrucción de los naturales ${ }^{18}$, medidas que, finalmente, no se aplicaron a cabalidad y quedaron prácticamente anuladas con la llegada de la Reconquista española en 1815.

Durante la Segunda República, se reanudaron los esfuerzos tendientes a extender los beneficios de la educación elemental a sectores marginales de la sociedad. En atención a los abusos ocurridos y a las especiales atenciones que merecía la comunidad indígena, “[...] por haber sido la más vejada, oprimida y degradada durante el despotismo español”, el presidente Simón Bolívar resolvió, mediante Decreto del 20 de mayo de 1820, que los productos de los arrendamientos de los resguardos debían destinarse exclusivamente al pago de tributos y al pago de los maestros de las escuelas instaladas en cada pueblo; se dispuso, además, que todos los indígenas entre 4 y 14 años debían asistir a la escuela, donde se les enseñarían las primeras letras, la aritmética, los fundamentos de la religión católica, los derechos y deberes del hombre y del ciudadano ${ }^{\mathbf{1 9}}$.

16. Jorge Orlando Melo. Francisco Antonio Moreno y Escandón: retrato de un burócrata colonial. En: Francisco Antonio Moreno y Escandón. Indios y mestizos de la Nueva Granada a finales del siglo XVIII (Bogotá: Banco Popular, 1985), 11-20.

17. Buenaventura Delgado Criado. Siglo XVIII, Política educativa. En: Buenaventura Delgado Criado (coord.). La educación en la España moderna (siglos XVI-XVIII) (Madrid: Ediciones Santa María, 1993), 651.

18. La Junta Suprema concede privilegios a los indios (Santafé, 1810), en: AGN, Sección Archivo Anexo, Fondo Historia, tomo 11, f. 226r.

19. Luis Horacio López Domínguez (comp.). De Boyacá a Cúcuta. Memoria Administrativa, 1819-1821 (Bogotá: Biblioteca de la Presidencia de la República, 1990), 189-191; Armando Martínez Garnica. El Régimen del Resguardo en Santander (Bucaramanga: Gobernación de Santander, 1993), 130. 
En el Decreto que dictara cinco meses más tarde, el vicepresidente Francisco de Paula Santander reiteró las antedichas medidas instauradas por Bolívar y aclaró que los vecinos blancos residentes en el pueblo indígena también se comprometían a aportar para el pago de los maestros; era responsabilidad de los gobernadores, jueces políticos y párrocos garantizar la instrucción a los indígenas "[...] para que puedan salir del embrutecimiento y condición servil a que por tantos años han estado sujetos" ${ }^{\mathbf{2 0}}$. En el informe publicado por el gobierno central sobre el balance de su gestión durante este año, se reconoció que "[...] jamás se les había proporcionado alguna educación para que, conservando siempre su estupidez, no pudiesen reclamar sus derechos"21.

Con miras a acogerse a las prerrogativas consagradas en estos avances normativos, el 31 de diciembre de 1820, los indios del pueblo de Firavitoba elevaron una súplica al Libertador Simón Bolívar en la que pedían protección ante los continuos abusos cometidos contra ellos, como el hecho de no haberse aún levantado escuela. Bolívar impartió instrucciones al gobernador de Tunja para que amparara a los indios en sus justas peticiones ${ }^{22}$.

En el debate de la Ley de creación de escuelas públicas, que tuvo lugar en el Congreso de Cúcuta en julio de 1821, el parlamentario Domingo Briceño había alertado sobre el problema de la demora en las ventas y remates de Resguardos, lo que, según él, se veía reflejado en la postergación de los beneficios estipulados por la ley ${ }^{23}$. Entre tanto, su colega Joaquín Borrero había puesto de presente que la fórmula de financiación de escuelas, propuesta por el vicepresidente Santander, podía quedar sin efecto si el gobierno decidía declarar a los indios en igualdad plena de derechos con el resto de ciudadanos, pues de esta forma ya no habría oficialmente tierras indígenas.

El diputado Félix José Blanco señaló el hecho de que había pueblos de indios tan pobres que se hacía prácticamente imposible establecer allí escuelas y, para ello, trajo a colación la experiencia de los pueblos del Casanare, que estaban bajo el cuidado de misioneros, caso en el que podía encargársele a ellos directamente la educación de los niños. Sobre este punto, el congresista Antonio Mendoza añadió que era indispensable que el gobierno enviara periódicamente comisionados para que examinaran si estos religiosos cumplían estrictamente con esta

20. Felipe Osorio Racines. Decretos del General Santander. 1819-1821 (Bogotá: Universidad Nacional, 1969), 155.

21. Alejandro Osorio y Estanislao Vergara, Los encargados de la Secretaría General del Departamento de Cundinamarca presentan a S. E. el General F. de P. Santander, vicepresidente del mismo Departamento, la memoria correspondiente al año de 1820 (Bogotá: Imprenta de Espinosa, 1821), 45.

22. Acotaciones Bolivarianas. Decretos marginales del Libertador (1813-1830) (Caracas: Fundación John Boulton, 1960), 108-109.

23. Actas del Congreso de Cúcuta 1821 (Bogotá: Biblioteca de la Presidencia de la República, 1990), Vol. 2, 48. 
tarea o, de lo contrario, se les retirara de esa función pastoral ${ }^{24}$. El diputado José Francisco Pereira apoyó estos argumentos y, en aras de la igualdad, lanzó una sugestiva idea al proponer que aquellos pueblos indígenas con bastantes tierras sobrantes contribuyeran solidariamente con aquellos pueblos humildes, que no contaban con el alivio de las rentas de arriendo de resguardos.

Como producto de estas discusiones, al fin, se promulgó la Ley del 2 de agosto de 1821 y allí se reiteró que las escuelas debían dotarse con el producto de los arrendamientos del sobrante de los resguardos y, adicionalmente, se les recordó a las personas no indígenas residentes en dichos espacios que debían aportar también para el sostenimiento de la escuela ${ }^{25}$.

A pesar de la buena intención de las tempranas leyes republicanas para garantizar la creación de escuelas en las comunidades indígenas, fue un proceso lento, que implicó la disponibilidad de un terreno para la sede educativa y la consecución inmediata de recursos para el pago de los maestros.

Desde los tiempos del dominio hispánico era evidente la problemática en los Resguardos, después de haber sido objeto de un drástico proceso de agregación y extinción a finales del siglo XVIII, lo que terminó por causar más desintegración y desarraigo en la población indígena: unos se negaron enfáticamente a salir de sus tierras y optaron por huir, algunos se resistieron a permanecer en el pueblo receptor, mientras que otros retornaron a su suelo original y tropezaron con no pocas dificultades y un ambiente lleno de conflictos interétnicos ${ }^{26}$.

Las medidas del Resguardo de Platanal, en el cantón de Vélez, las efectuaron el $1^{\circ}$ de noviembre de 1821 y, según los cálculos del alarife José Antonio Vargas, abarcaban 959 cuadras, que equivalían a 2 estancias y 54 cuadras, de las cuales un pedazo de tierra de 165 cuadras se había destinado para la escuela. A pocas leguas de allí, en el pueblo indígena de Onzaga, se señaló el terreno para la escuela, pero por su carácter montuoso se hacía imposible medirlo; se apartó, además, un pedazo del resguardo para arrendarlo y, con su producto, pagar anualmente al maestro; otro pedazo de tierra se remató en 30 pesos al cura Ignacio Díaz; el valor restante, es decir 150 pesos, correspondiente a la dotación asignada a esta parroquia para la escuela, lo asumirían equitativamente los vecinos ${ }^{27}$.

Domingo Guerrero, comandante militar del cantón de Carcasí, en la provincia de Pamplona, solicitó, el 6 de diciembre de este mismo año, al Secretario

24. Actas del Congreso de Cúcuta 1821, Vol. 2, 59, 87.

25. Actas del Congreso de Cúcuta 1821, Vol. 2, 159.

26. Véase: Roger Pita Pico. El remate de resguardos en el nororiente neogranadino durante el siglo XVIII. En: Boletín de Historia y Antigüedades, Vol. XCIV, No. 839 (oct.-dic., 2007): 725-748.

27. Diligencias de medición de resguardos en el cantón de Vélez (Vélez, 1821). En: Archivo General de la Nación, Sección República, Fondo Miscelánea. Tomo 123, ff. 34r, 61v. 
del Interior, aplicar los productos de sus resguardos para erigir una escuela de primeras letras, sin cuyo auxilio se hacía imposible su sostenimiento. Tiempo atrás, el vicepresidente Santander había decidido aplicar dichos recursos para la escuela de Málaga, pero esta villa contaba con un buen número de habitantes y recursos suficientes para sostenerse sin aquel auxilio, mientras que los de Carcasí, por su situación de estrechez económica, jamás podían alcanzar su meta sin contar con esa renta; a los quince días, el Secretario del Interior José Manuel Restrepo expresaba, desde Bogotá, su aprobación a esta solicitud ${ }^{\mathbf{2 8}}$.

Los indios de Carcasí tenían en el área de la parroquia un globo de tierras que permanecía arrendado y otro que, por vía de donación, les había otorgado años antes un vecino de este lugar; en vista de que los nativos no utilizaban este último pedazo de tierra, se solicitó que se aplicara al pago del maestro de la escuela y que los vecinos respondieran por lo que faltara hasta completar los 150 pesos, que era el costo anual del servicio del maestro; los indígenas convinieron en esta decisión al aducir que esas tierras no las necesitaban ni para sus labores ni para sus viviendas, pues se hallaban bien acomodados en otro globo de tierra que poseían por la donación hecha por el prestante vecino don Lorenzo de Rojas, en premio del trabajo y servicio brindados; lo que sí dejaron en claro fue que el producto del globo destinado a favor de la escuela generalmente ingresaba a las arcas oficiales de la ciudad de Pamplona, pero de esos recursos jamás habían tenido noticia. Al indagarse a las autoridades del fisco, se comprobó que anualmente los ciudadanos Manuel Salvador Castellanos y Juan Pablo Duarte consignaban 30 pesos anuales en calidad de arrendatarios de esos terrenos.

Ante tantas complicaciones, a veces resultaba más expedita la gestión e iniciativa particular de los curas. El presbítero Francisco Javier de Figueroa, cura del pueblo de indios de Puracé, en el Cauca, estableció, a principios de 1823, una escuela de primeras letras en la que matriculó a más de 60 chiquillos; él mismo costeó la entrega de cartillas para cada alumno y se dio a la tarea de persuadir al vecindario blanco para que, con su contribución, se financiara el sueldo del maestro. En las páginas del semanario El Fósforo de Popayán se exaltó la "laudable" labor de este cura como un ejemplo a seguir ${ }^{29}$.

Las posibilidades de acceso a la educación secundaria se tornaron más engorrosas para la juventud indígena; el vicepresidente Santander quiso transformar este panorama y, para ello, dictó el Decreto del 11 de marzo de 1822, en el que enfatizó en la importancia de sacar a los nativos del estado de "abatimiento e ignorancia" en que se hallaban, condición que se consideraba un legado funesto del sistema legislativo español.

28. Archivo General de la Nación, f. 2r.

29. El Fósforo de Popayán, Popayán, marzo 26 de 1823, 68. 
Para superar esta situación, Santander tenía la convicción de que uno de los medios más poderosos era extender a este grupo los beneficios de la educación; así, entonces, dispuso que, en todos los Colegios Seminarios debía admitirse a los indios "puros" en una fase inicial, en la que al menos cuatro de ellos los recibirían en el Colegio de Bogotá, cuatro en el de Caracas e igual número en el de Quito, y dos en cada uno de los demás Colegios de la República. Los aspirantes debían cumplir con el requisito de saber leer y escribir correctamente y el proceso de selección quedó a cargo de los directores, que tendrían en cuenta a los más adelantados y de mejor disposición para el estudio, previos informes remitidos por los curas y los directores de las escuelas parroquiales.

En razón a la pobreza de este sector de la sociedad y la atención especial que "merecían", se dispuso que de los Fondos públicos, se le entregara a cada becado un total de 120 pesos anuales para su vestuario y los útiles escolares básicos. Los rectores de los colegios debían cuidar "paternalmente" a estos educandos, mientras que a los obispos y curas les correspondía la labor de acompañamiento para el fiel cumplimiento de este mandato ${ }^{30}$.

En la práctica, se observó que las becas otorgadas a los indígenas no las financió propiamente el Estado central, sino se recurrió también a las donaciones de particulares y a los réditos obtenidos de los arriendos de los resguardos, que debían alcanzar también para la fundación de escuelas.

Ante la escasez de fondos y en vista del escaso número de indios y del amplio espacio de las tierras de resguardo que permanecían aún improductivas, la $S o$ ciedad de amigos del país, de la villa de Medellín, tramitó, en abril de 1822, ante el gobierno central la adjudicación de los sobrantes de los resguardos, con el propósito de fundar un colegio después de que quedaran suficientemente dotadas las escuelas de primeras letras de cada uno de esos poblados. El gobierno, previo informe del cabildo, avaló este proyecto y comisionó al señor Joaquín Velásquez para que dividiera y procediera a rematar el arriendo de los terrenos sobrantes ${ }^{\mathbf{3 1}}$.

Aparentemente, estas diligencias no arrojaron frutos concretos y no fue sino hasta el 9 de octubre cuando el gobierno nacional dispuso, por decreto, que una de las fuentes de financiación para el recién creado colegio de Antioquia fuera 500 pesos de los arrendamientos de los sobrantes de los resguardos de las parroquias de indígenas de la provincia; de esta suma, debía apartarse lo necesario para costear la beca de cuatro niños indígenas que contaran con las cualidades contempladas en el Decreto del 11 de marzo de $1822^{32}$. Pese a estas

30. Luis Horacio López Domínguez (comp.). Obra educativa de Santander, 1819-1826 (Bogotá: Biblioteca de la Presidencia de la República, 1990), 57-58.

31. El Eco de Antioquia, Medellín, junio 23 de 1822, 29.

32. Gaceta de Colombia, Bogotá, octubre 27 de 1822, 1. 
disposiciones, seguían persistiendo algunas dificultades en la consecución de estas rentas; en 1823, por ejemplo, el intendente de Cundinamarca impartió orden al gobernador de Antioquia para que detuviera el proceso de arrendamiento de tierras indígenas ubicadas en la parroquia de La Estrella ${ }^{33}$.

A finales de 1822, el gobierno central continuó empeñado en el desarrollo educativo a nivel regional y para ello creó el Colegio de San Simón, de la ciudad de Ibagué; en esta ocasión, se dispuso que se destinarían 900 pesos anuales, de los sobrantes de los arrendamientos de los Resguardos de las provincias de Neiva y Mariquita, recursos con los que debían constituirse seis becas ${ }^{34}$.

El vicepresidente Santander dio vía libre, el 29 de enero de 1823, para fundar el Colegio de Santa Librada, en la ciudad de Cali. Con los fondos destinados para este establecimiento, había que patrocinar ocho becas, de 100 pesos cada una, de las cuales dos eran para los indígenas de la provincia de Popayán y otras dos para los del Chocó ${ }^{35}$.

El 21 de noviembre de 1824 abrió sus puertas el Colegio de Santa Marta, creado en respuesta al Decreto del gobierno y a las diligentes gestiones de su director, el provisor gobernador del obispado Francisco Timoteo Rivera; el acto inaugural se celebró con misa de acción de gracias, Te Deum y otras expresiones de alegría, a los que concurrieron las autoridades y los vecinos más distinguidos de la ciudad; catorce jóvenes, entre los cuales se contaban varios indígenas, recibieron beca para cursar sus estudios ${ }^{36}$.

Las pocas evidencias encontradas sobre iniciativas privadas de patrocinio de becas para indígenas correspondían casi siempre a regiones prósperas de la República. En la villa de San Gil, el recién creado Colegio de San José de Guanentá recibió un incentivo de manos de su propio rector, el cura Francisco José Otero, quien decidió donar 900 pesos, representados en nueve becas, para repartirse entre niños pobres e indígenas de aquella jurisdicción ${ }^{37}$.

Por esta misma época, habría que mencionar el caso especial de Blas Torres, nativo descendiente de los caciques de Mamatoco, en la provincia de Santa Marta, quien tomó, a principios de 1824, la beca en el Colegio Mayor del Rosario de la ciudad de Bogotá, apadrinado por el vicepresidente Santander, noticia a la que se

33. El Eco de Antioquia, Medellín, enero 26 de 1823, 147.

34. Gaceta de Colombia, Bogotá, diciembre 29 de 1822, 1.

35. Gaceta de Colombia, Bogotá, marzo 30 de 1823, 1.

36. Gaceta de Colombia, Bogotá, enero 23 de 1825, 2.

37. Juan de Dios Arias. Colegio de San José de Guanentá. Reseña histórica (Bucaramanga: Editorial Gómez \& Páez, 1943), 24. 
le dio todo el realce, pues apareció publicada en la prensa oficial ${ }^{38}$; como alumno externo, dos años estudió Torres la cátedra de filosofía ${ }^{39}$.

En términos generales, muy pobres fueron los resultados de las medidas educativas de carácter incluyente dictadas por el Estado republicano. En realidad, el gobierno central no realizó un seguimiento estricto a sus disposiciones, mientras que las autoridades provinciales se preocuparon por enviar datos y cifras globales, pero sin especificar los avances en materia de oportunidades educativas para la población indígena.

Más desoladora era la situación para los indios denominados "salvajes", es decir, los que vivían en lugares remotos y no se sujetaban al régimen republicano ni a la labor pastoral de la Iglesia. El 29 de abril de 1826, el vicepresidente Santander determinó que a las tribus que habitaban las costas de la Guajira, el Darién, Mosquitos y las demás "no civilizadas" las protegerían y tratarían como colombianos dignos de atención especial por parte del gobierno. El poder ejecutivo quedó facultado para procurar que estas tribus entraran en contacto con las poblaciones vecinas ${ }^{40}$; sin embargo, como bien se sabe, estas comunidades mantendrían su resistencia durante muchas décadas; así, entonces, faltaba mucho trecho para incorporarlas a la sociedad republicana y aún más lejana era para ellas la posibilidad de ingresar a la educación formal.

\section{EDUCAR A LOS NEGROS: ENTRE TEMORES E INCERTIDUMBRES}

No se debe olvidar que, en la escala del régimen colonial, la población negra era la más segregada por ocupar el último peldaño de la estructura social, y la legislación no hizo más que refrendar esa condición de inferioridad. Al negro, tanto libre como esclavo, lo subestimaron por su origen africano; con frecuencia, su mismo color de piel le rotulaba una serie de tachas, tales como: borracho, grosero, ladrón, perezoso, pendenciero, por solo señalar unas cuantas. El hombre blanco lo percibía con desprecio y constantemente se refería a él con expresiones desdeñosas, como "vil", "bárbaro" o "miserable". Por lo general, se los consideraba con menores capacidades mentales para asumir determinadas funciones y se les vedaba el acceso a cargos eclesiásticos y políticos.

Aún en contra de esta estigmatización y de las reconocidas restricciones ${ }^{41}$ para asistir a un aula de clases, se sabe que algunos esclavos aprendieron a leer y escribir, tal como lo evidencian algunas cartas dirigidas a las autoridades,

38. Gaceta de Colombia, Bogotá, febrero 8 de 1824, 1.

39. María Clara Guillén de Iriarte. Restricciones en la educación para los indígenas americanos. El caso del Nuevo Reino de Granada. En: Boletín de Historia y Antigüedades, Vol. LCVI, No. 845 (2009), 418.

40. Gaceta de Colombia, Bogotá, mayo 21 de 1826, 1.

41. Por su misma condición de subyugación, las comunidades negras padecieron serias restricciones en materia de movilidad. 
casi siempre en procura de mejoras en el trato y en sus condiciones de vida; en ocasiones, ese aprendizaje básico pudo ser posible gracias al acercamiento afectivo con los amos.

En 1797, en Ocaña, la negra María Isabel Noriega acudió ante la justicia para que se le reconociera la herencia que le correspondía a su difunto hijo Juan Antonio, cuyo padre era su propio amo, don Dionisio Noriega; varios testimonios dieron cuenta de la acogida que el fruto de esa unión ilegal tuvo dentro de la familia paterna; el testigo Miguel Antonio Rizo confirmó esa protección y tutelaje: "[...] distinguido en la educación, crianza y asistencia, pues fue estimado por el padre del citado Noriega y también su hermano Juan Bauptista, en tal conformidad que cuidaron aprendiese a leer y escribir perfectamente, manteniéndolo siempre con la decencia correspondiente a un hijo legítimo"42.

La Cédula real del 31 de mayo de 1789, llamada también "Código Carolino

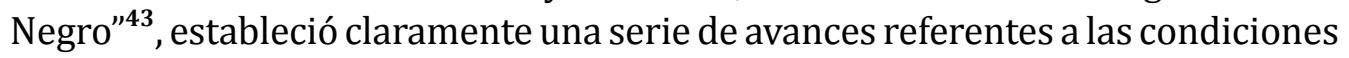
sociales de los esclavos, al obligar a los dueños a socorrer de manera especial a los niños; al amo que no asegurara instrucción religiosa, educación y atención básica, se le impondría una multa de cincuenta pesos por la primera vez y cien a los reincidentes ${ }^{44}$. En este caso se hablaba de educación en términos genéricos, pero sin especificar el compromiso de garantizar el ingreso a la escuela. A pesar de que esta Ley se suspendió, a raíz de la airada protesta de los amos, de todas maneras sentó un precedente en cuanto al trato humanitario; a los pocos años recobró su vigencia, que se extendió hasta la abolición definitiva de la esclavitud en 1852.

El trato a los negros, durante el periodo de la naciente República, se marcó por la continuidad del sistema esclavista ante los frustrados intentos de la dirigencia criolla para conciliar la independencia política con las tesis abolicionistas ${ }^{45}$. Sobre la formación educativa, los avances fueron realmente insignificantes; la mayoría de las veces se dictaron normas que se quedaron en meras intenciones o simplemente se abolían ante los cambios súbitos de gobierno, en razón a la lucha independentista. El quiteño Antonio Villavicencio había propuesto, en 1809,

42. María Isabel Noriega, su solicitud de carta de libertad para su hijo (Ocaña, 1797). En: Archivo General de la Nación, Sección Colonia, Fondo Negros y Esclavos de Santander. Tomo 4, f. 698r.

43. Este fue el primer y único compendio normativo coherente en el tratamiento humanitario, durante el tiempo de dominio indiano, que contrastó con las leyes anteriores, marcadamente represivas.

44. Cédula Real del 31 de mayo de 1789 sobre trato a los esclavos (Santafé, 1789). En: Archivo General de la Nación, Sección Archivo Anexo, Fondo Reales Cédulas y Órdenes. Tomo 29, f. 62v.

45. Roger Pita Pico. El trato a los esclavos durante la Independencia de Colombia: rupturas y continuidades en una etapa de transición política. En: Boletín de Historia y Antigüedades, Vol. XCIX, No. 854 (en.-jun., 2012), 117. 
que los hijos de las esclavas debían asistir a una escuela pública de enseñanza de oficios, que costearía el gobierno ${ }^{46}$.

Durante la Primera República Federativa, se registraron algunos avances en el reconocimiento de los derechos de los esclavos. En el Estado provincial de Antioquia, bajo el liderazgo de Juan del Corral y Félix de Restrepo, se aprobó, en abril de 1814, la considerada Primera Ley de manumisión en Colombia; allí se intentaron armonizar los ideales republicanos con la redención de los hombres en estado de esclavitud; en el marco de aquel derrotero, se consideraba de gran relevancia, para el naciente proyecto político, el cambio del destino que los esclavos habían sufrido durante los tiempos del dominio hispánico, tratados vilmente, equiparados a las bestias y privados de una adecuada educación; como aspecto central, se estipuló la Ley de partos, en la cual se les señaló a los amos la responsabilidad de mantener y educar a los hijos de sus esclavas hasta los 16 años, cuando debían quedar libres ${ }^{47}$.

La recuperación del poder por parte de los españoles, tras la arremetida de las fuerzas de Reconquista en los años de 1815 y 1816, implicó la suspensión de estas medidas progresistas. En tiempos de la Segunda República, se reanudó la discusión sobre las tesis abolicionistas y sobre el imperativo de procurar una mejora en las condiciones sociales de la población esclava. La Ley de manumisión del 11 de enero de 1820, en su Artículo 3o planteó la necesidad de “[...] promover activamente la primera civilización de los esclavos, por medio de diversas instituciones, enseñando a leer y escribir a los niños, dando a todos en general alguna idea de los deberes sociales, inspirándoles amor al trabajo y a las virtudes públicas, y haciendo depender de ellas mismas la más o menos pronta posesión de su libertad" ${ }^{48}$.

En el marco de la Ley de partos, dictada el 21 de julio del año siguiente, a los dueños de esclavas les quedó fijada la precisa obligación de educar a los hijos de ellas, pero a estos jóvenes se les amplió a 18 años el tiempo de servicio ${ }^{49}$.

Con la expedición de este par de leyes, surgieron más voces que hablaban sobre la necesidad estratégica de formar adecuadamente a los libertos, principalmente en su comportamiento y virtudes morales; todavía estaba latente el temor entre los amos y las autoridades, tras la experiencia revolucionaria prota-

46. Biblioteca Nacional de Colombia (BNC), Fondo Manuscritos. Abolición de la esclavitud en ambas Américas (Sevilla, 1809), libro 435, ff. 48r-54r.

47. Gazeta Ministerial de la República de Antioquia, Medellín, octubre 2 de 1814, 6-7.

48. Correo del Orinoco (Angostura, Venezuela) 1818-1821 (Bucaramanga: Gerardo Rivas Moreno Editor, 1998), 205.

49. Ley de manumisión del 21 de julio de 1821 (Bogotá, 1821). En: Archivo General de la Nación, Sección Archivo Anexo, Fondo Gobierno Civil. Tomo 38, f. 514r. 
gonizada por los negros en Haití ${ }^{50}$; entonces, la idea era prepararlos para asumir la nueva vida libre y evitar que incurrieran en sublevaciones o indisciplinas que atentaran contra el sosiego público; así, por ejemplo, en un Memorial, publicado en 1825, el senador Joaquín Mosquera creyó irresponsable extinguir la esclavitud en pocos años sin mejorar gradualmente la educación civil y moral de esta población, instrucción que, según él, debía ser responsabilidad del Estado ${ }^{51}$.

Fueron, en realidad, muy escasas las propuestas concretas dirigidas a garantizar la educación básica a la población negra y, por lo general, correspondían a iniciativas puntuales de algunas autoridades regionales o de empresarios esclavistas.

En febrero de 1822 el intendente del Cauca, José Concha, instó a las autoridades del cantón de Iscuandé para que invitaran a los amos a destinar a aquellos jóvenes negros, que no fueran útiles para el trabajo, para que aprendieran a leer, escribir y contar números, para lo que exigió un informe periódico sobre los alcances de esta medida ${ }^{52}$. Al año siguiente, el empresario minero Antonio Arboleda fundó una escuela de primeras letras en su mina Santamaría, localizada en jurisdicción de Caloto, en la provincia de Popayán; en este centro de producción aurífera, Arboleda concentraba la mayor cantidad de su mano de obra esclava y a esa misma escuela concurrían también niños esclavos de otros propietarios mineros ${ }^{53}$.

Paradójicamente, aun por encima de todas las limitaciones inherentes a su condición social, algunas esclavas dedicadas al servicio doméstico influyeron notablemente en la formación de los hijos de sus amos, de lo que pudo dar fe el oficial patriota José Hilario López, quien, en 1823, regresó a Popayán, tras haber padecido varios años de ultrajes durante la represión española; en su largo destierro, sus dos pequeños hermanos huérfanos quedaron bajo el amparo de su esclava Antonia, quien, además, se preocupó porque aprendieran a leer, escribir y contar; como prueba de gratitud por estos invaluables servicios, López le concedió a Antonia carta de libertad y prometió brindarle toda la protección posible ${ }^{54}$.

Todo indica que la comunidad de negros y mulatos libres aumentó, especialmente en los primeros años de vida republicana, en razón a los ofrecimientos

50. Marixa Lasso. Haití como símbolo republicano popular en el Caribe colombiano: provincia de Cartagena (1811-1828). En: Historia Caribe, Vol. III, No. 8 (2003): 5-18.

51. Joaquín Mosquera. Memoria sobre la necesidad de reformar la ley del Congreso Constituyente de Colombia, de 21 de Julio de 1821, que sancionó la libertad de los partos, manumisión y abolición del tráfico de esclavos, y bases que podrían adoptarse para las reformas (Bogotá: F. M. Stokes, 1825), 8.

52. Informe del intendente del Cauca (Popayán, 1822). En: Archivo Central del Cauca (ACC), Sala Independencia, Civil I-2 Gobierno, signatura 6.839, f. 33r.

53. El Fósforo de Popayán, Popayán, mayo 15 de 1823, 121.

54. José Hilario López, Memorias (Bogotá: Editorial ABC, 1942), tomo I, 125. 
hechos a cambio del servicio de las armas y de los beneficios contemplados por las leyes de manumisión, pero las expectativas para estas gentes de ébano, que estrenaban su libertad, se avizoraban bastante inciertas debido a la crisis económica derivada de la guerra; intensos debieron ser los esfuerzos para sobrevivir en un ambiente con escasas opciones de ascenso social y con la persistencia de fuertes prejuicios en relación con estos descendientes de esclavos.

Con la creciente comunidad de afrodescendientes libres, el camino hacia el reconocimiento de la ciudadanía no fue tan fácil como se pensaba; ni siquiera con los nuevos aires progresistas que ofreció el fragor independentista, de los años iniciales del siglo XIX, se les quiso reconocer plenos derechos igualitarios.

Al obtener el reconocimiento como ciudadanos, los libres descendientes de esclavos recibían automáticamente ventajas, como la igualdad ante la ley, el derecho a disponer de sí mismos, el derecho a la propiedad y la libertad de cultivo, entre otras, pero, por otro lado, se les cerró el camino en materia electoral y en acceso a educación y a ciertos empleos; sólo con el paso del tiempo, algunos libres descendientes de esclavos, blanqueados por efecto de los azares de la mezcla interétnica, contaron con mayores esperanzas de acceder a la educación formal, en la cual los blancos seguían siendo el segmento poblacional privilegiado.

Tal como se puede colegir de este análisis, la población negra fue mucho más relegada que los indígenas, en los planes de expansión educativa; únicamente se registraron iniciativas muy aisladas o, en otros casos, se suscribieron intenciones muy generales sobre la necesidad de educarlos, pero sin estipularse mecanismos claros y verificables de ingreso a las escuelas y colegios.

\section{CONCLUSIONES}

Las ambiciosas metas educativas trazadas por el naciente gobierno republicano, concebidas como eje nodal del progreso nacional, sobrepasaron ampliamente las posibilidades reales de ejecución; muy poco impacto tuvieron estas políticas en los estratos bajos y en las minorías étnicas; apenas un reducido número de indios y negros infantes y jóvenes pudieron ingresar a un aula de clase; enviar a estos pequeños a clases implicaba muchas veces una logística y recursos para movilizarse hasta la cabecera urbana más cercana, operación que no resultaba fácil para todos.

Aquellos casos en que se abrieron algunas oportunidades se daban en las principales ciudades o en las localidades más prósperas, pero la situación se tornó más complicada en aquellos lugares distantes y marginados de la República. La falta de recursos estatales para cumplir las metas propuestas fue un 
factor que les permitió a las comunidades religiosas mantener por más tiempo el monopolio de la educación en algunas comunidades indígenas ${ }^{55}$.

Las dificultades en el acceso a la educación escolarizada para los indígenas y negros se incrementaron a medida que se avanzaba en la escala educativa, lo que permite comprender por qué las talanqueras para formarse en instituciones superiores y seminarios se acentuaron más pues, desde la época colonial e incluso en los primeros años de vida republicana, estos establecimientos se reservaban exclusivamente para la nobleza local. El Colegio Mayor de San Bartolomé, el Colegio Mayor del Rosario y la Universidad Tomista incluyeron, en sus procesos de admisión, severas pruebas de limpieza de sangre y nacimiento legítimo, además de tener que comprobar que sus ascendientes no se hubiesen mezclado con gentes de "malas razas", es decir, con negros o indios ${ }^{56}$. Un avance se registró hacia 1825, al decretarse que la condición de ilegitimidad no era impedimento para obtener grados universitarios ${ }^{57}$.

Es indudable que, durante el periodo estudiado de la naciente República, aún pervivían rezagos de la mentalidad conservadora del antiguo régimen colonial. Los principios de igualdad y libertad, proclamados por los dirigentes republicanos, muy poco se vieron reflejados en el desarrollo y puesta en práctica de la política educativa para los indios y los negros. En este sentido, estos individuos fueron ciudadanos de segunda, pues nunca estuvieron en el orden de prioridades a la hora de diseñar planes de cobertura y esquemas de financiación. Así, se estableció una paradoja y una contradicción entre los derechos ciudadanos proclamados por la Ilustración del siglo XVIII y el pensamiento liberal del siglo XIX y, por otro lado, la persistencia de las diferencias raciales y las restricciones inherentes a este sistema, con lo que se impidió la consolidación de un proyecto nacional moderno ${ }^{58}$.

En términos generales, se observa que la clase dirigente republicana otorgó, en el plano de lo discursivo, algunas concesiones a los sectores bajos de la población, pero la falta de voluntad política hace pensar seriamente que, en realidad,

55. Martha Cecilia Herrera. Las mujeres en la historia de la educación. En: Magdalena Velásquez Toro. Las mujeres en la historia de Colombia (Bogotá: Editorial Norma, 1995), Tomo I, 334.

56. Véase: Roger Pita Pico. Nobleza y limpieza de sangre en el nororiente neogranadino, 1710-1810: entre la segregación y la amenaza étnica. En: Procesos Históricos: Revista de Historia y Ciencias Sociales, Año XII, No 24 (jul.-dic., 2013): 16-43; María Clara Guillén de Iriarte. Nobleza e Hidalguía en el Nuevo Reino de Granada. Colegio Mayor de Nuestra Señora del Rosario 1651-1820 (Santafé de Bogotá: Ediciones Rosaristas, 1994), Tomo II: 697-764; William Jaramillo Mejía. Real Colegio Mayor y Seminario de San Bartolomé. Nobleza e Hidalguía (Bogotá: Instituto Colombiano de Cultura Hispánica, 1996): 893-912.

57. Gaceta de Colombia, Bogotá, mayo 15 de 1825, 1.

58. María Eugenia Chaves. Los sectores subalternos y la retórica libertaria. Esclavitud e inferioridad racial en la gesta independentista. En: Guillermo Bustos y Armando Martínez Garnica (eds.). La Independencia en los países andinos. Nuevas perspectivas (Bucaramanga: Organización de Estados Iberoamericanos/ Universidad Andina Simón Bolívar, 2004), 218. 
esa élite se aseguró de mantener intactos sus privilegios como grupo dominante de la estructura social, prerrogativas heredadas desde la época colonial.

Sin embargo, se debe registrar el liderazgo del vicepresidente Santander, quien, de forma insistente, se preocupó por sacar adelante algunas ideas dirigidas a lograr una mayor cobertura en materia educativa ${ }^{59}$. En igual sentido, resulta válido resaltar el papel asumido por la prensa, no sólo de carácter oficial, sino también de otros sectores de opinión, tanto de la capital como a nivel provincial, que convirtió a estos medios en constantes voceros de los progresos educativos y, simultáneamente, en espacios a través de los cuales se lanzaron serias críticas y recomendaciones con el propósito de tener una política educativa más eficiente e incluyente.

A fin de cuentas, no se les compensó debidamente a estos grupos el esfuerzo de haber contribuido a la causa patriota ${ }^{60}$. Tales inequidades en el acceso de la educación siguieron presentándose en buena parte del siglo XIX ${ }^{61}$. En últimas, este tardío reconocimiento de los derechos educativos generó un retraso en las oportunidades de ascenso social y económico para los sectores afectados, lo que aplazó por mucho más tiempo las posibilidades de escalar hasta los espacios de poder y de decisión política, con lo cual se aumentó indefectiblemente la brecha de desarrollo formativo en estos primeros años de vida republicana.

59. Sobre el fundamento ideológico de la transformación educativa de Santander, véase Carlos A. Rosso. La obra educativa del general Santander. En: Revista Historia y Espacio, No. 24 (2003): 39-78.

60. Véase: Javier Ocampo López. El proceso político, militar y social de la Independencia. En: Nueva Historia de Colombia (Bogotá: Editorial Planeta, 1989), Tomo II, 27-29; Roger Pita Pico. El reclutamiento de negros esclavos durante las guerras de Independencia de Colombia 1810-1825 (Bogotá: Academia Colombiana de Historia, 2011): 39-215.

61. Magnolia Aristizábal. Cuerpo, ciudadanía, subjetividad: la relación de tres conceptos en la educación de la mujer del siglo XIX. En: Revista Historia de la Educación Colombiana, No. 8 (2005), 121-122. 


\section{REFERENCIAS BIBLIOGRÁFICAS}

\section{Documentos de Archivo}

Archivo Central del Cauca (ACC), Popayán-Colombia. Sala Independencia.

Archivo General de la Nación (AGN), Bogotá-Colombia. Fondos: Gobierno Civil, Historia, Instrucción Pública, Miscelánea, Negros y Esclavos de Santander, Reales Cédulas y Órdenes.

Biblioteca Nacional de Colombia (BNC), Bogotá-Colombia. Fondo Manuscritos.

\section{Fuentes primarias impresas y fuentes secundarias}

Acotaciones Bolivarianas. Decretos marginales del Libertador (1813-1830). Caracas: Fundación John Boulton, 1960.

Actas del Congreso de Cúcuta 1821. Vol. 2. Bogotá: Biblioteca de la Presidencia de la República, 1990.

Arias, Juan de Dios. Colegio de San José de Guanentá. Reseña histórica. Bucaramanga: Editorial Gómez \& Páez, 1943.

Arboleda Niño, Juan Ignacio. Entre la libertad y la sumisión. Estrategias de liberación de los esclavos en la gobernación de Popayán durante la Independencia, 1808-1830. Bogotá: Departamento de Historia de la Universidad de los Andes, 2006 (Documento CESO No. 110).

Aristizábal, Magnolia. Cuerpo, ciudadanía, subjetividad: la relación de tres conceptos en la educación de la mujer del siglo XIX. En: Revista Historia de la Educación Colombiana, No. 8 (2005): 117-134.

Caldas, Francisco José de. Estudios varios. Bogotá: Ministerio de Educación Nacional, 1941.

Calderón Rodríguez, Luis Antonio. La Ilustración francesa y su influencia ideológica en Colombia. Manizales: Universidad de Caldas, 2001.

Chaves, María Eugenia. Los sectores subalternos y la retórica libertaria. Esclavitud e inferioridad racial en la gesta independentista. En: Guillermo Bustos y Armando Martínez Garnica (eds.). La Independencia en los países andinos. Nuevas perspectivas. Bucaramanga: Organización de Estados Iberoamericanos/Universidad Andina Simón Bolívar, 2004).

Correo del Orinoco (Angostura Venezuela), 1818-1821. Bucaramanga: Gerardo Rivas Moreno Editor, 1998.

Delgado Criado, Buenaventura. Siglo XVIII, Política educativa. En: Delgado Criado, Buenaventura (coord.). La educación en la España moderna (siglos XVI-XVIII). Madrid: Ediciones Santa María, 1993.

El Eco de Antioquia. Medellín: Imprenta del Gobierno por Manuel María Viller-Calderón, 1822.

El Fósforo de Popayán, Popayán: Imprenta del Gobierno por Rafael Viteri, 1823.

Gaceta de Colombia. Bogotá: Imprenta de Espinosa, 1822-1826.

García Sánchez, Bárbara Yadira. De la educación doméstica a la educación pública en Colombia. Transiciones de la Colonia a la República. Bogotá: Universidad Distrital Francisco José de Caldas, 2007.

Gazeta Ministerial de la República de Antioquia. Medellín: Imprenta del Estado por el ciudadano Manuel María Viller-Calderón, 1814.

Guichot Reina, Virginia. Historia de la educación: reflexiones sobre su objeto, ubicación epistemológica, devenir histórico y tendencias actuales. En: Revista Latinoamericana de Estudios Educativos, Vol. 2, No. 1 (en.-jun., 2006): 11-51.

Guillén de Iriarte, María Clara. Restricciones en la educación para los indígenas americanos. El caso del Nuevo Reino de Granada. En: Boletín de Historia y Antigüedades, Vol. LCVI, No. 845 (2009): 409-418. 
Gutiérrez de Pineda, Virginia y Roberto Pineda Giraldo. Miscegenación y cultura en la Colombia colonial, 1750-1810. Tomo I. Bogotá: Ediciones Uniandes, 1999.

Hernández de Alba, Guillermo (comp.). Documentos para la historia de la educación en Colombia. Tomo V. Bogotá: Editorial Kelly, 1983.

Herrera, Martha Cecilia. Las mujeres en la historia de la educación. En: Magdalena Velásquez Toro. Las mujeres en la historia de Colombia (Tomo I. Mujeres, historia y política: 334-354). Bogotá: Editorial Norma, 1995.

Jaramillo Uribe, Jaime. Ensayos de Historia Social. Bogotá: Tercer Mundo/Ediciones Uniandes, 1989.

Lasso, Marixa. Haití como símbolo republicano popular en el Caribe colombiano: provincia de Cartagena (1811-1828). En: Historia Caribe, Vol. III, No. 8 (2003): 5-18.

Londoño Vega, Patricia y Santiago Londoño Vélez. Los niños que fuimos. Huellas de la infancia en Colombia. Bogotá: Banco de la República, 2012.

López, José Hilario. Memorias. Tomo I. Bogotá: Editorial ABC, 1942.

López Domínguez, Luis Horacio (comp.). De Boyacá a Cúcuta. Memoria Administrativa, 1819-1821. Bogotá: Biblioteca de la Presidencia de la República, 1990.

López Domínguez, Luis Horacio (comp.). Obra educativa de Santander 1819-1826. Vol. 1. Bogotá: Biblioteca de la Presidencia de la República, 1990.

Martínez Garnica, Armando. El Régimen del Resguardo en Santander. Bucaramanga: Gobernación de Santander, 1993.

Melo, Jorge Orlando. Francisco Antonio Moreno y Escandón: retrato de un burócrata colonial. En: Francisco Antonio Moreno y Escandón. Indios y mestizos de la Nueva Granada a finales del siglo XVIII. Bogotá: Banco Popular, 1985.

Mosquera, Joaquín. Memoria sobre la necesidad de reformar la ley del Congreso Constituyente de Colombia, de 21 de Julio de 1821, que sancionó la libertad de los partos, manumisión y abolición del tráfico de esclavos, y bases que podrían adoptarse para las reformas. Bogotá: F. M. Stokes, 1825.

Neissa de Mantilla, Ana Carmen. La evolución del pensamiento educativo de Simón Bolívar. Principios vigentes en los modelos pedagógicos del tercer milenio. Bogotá: Gente Nueva Editorial, 2005.

Ocampo López, Javier. El proceso político, militar y social de la Independencia. En: Nueva Historia de Colombia (Tomo II: 9-64). Bogotá: Editorial Planeta, 1989.

Osorio Racines, Felipe. Decretos del General Santander. 1819-1821. Bogotá: Universidad Nacional, 1969.

Osorio, Alejandro y Estanislao Vergara. Los encargados de la Secretaría General del Departamento de Cundinamarca presentan a S. E. el General F. de P. Santander, vicepresidente del mismo Departamento, la memoria correspondiente al año de 1820. Bogotá: Imprenta de Espinosa, 1821.

Pita Pico, Roger. Nobleza y limpieza de sangre en el nororiente neogranadino, 1710-1810: entre la segregación y la amenaza étnica. En: Procesos Históricos: Revista de Historia y Ciencias Sociales, № 24, Año XII (jul.-dic. 2013):16-43.

Pita Pico, Roger. El trato a los esclavos durante la Independencia de Colombia: rupturas y continuidades en una etapa de transición política. En: Boletín de Historia y Antigüedades, Vol. XCIX, No. 854 (en.-jun., 2012): 81-121.

Pita Pico, Roger. El remate de resguardos en el nororiente neogranadino durante el siglo XVIII. En: Boletín de Historia y Antigüedades, Vol. XCIV, No. 839 (oct.-dic., 2007): 725-748.

Pita Pico, Roger. El reclutamiento de negros esclavos durante las guerras de Independencia de Colombia 1810 1825. Bogotá: Academia Colombiana de Historia, 2011.

Rodríguez Plata, Horacio. La antigua provincia de Socorro y la Independencia. Vol. 48. Bogotá: Biblioteca de Historia Nacional, 1963.

Rosso, Carlos A. La obra educativa del general Santander. En: Revista Historia y Espacio, No. 24 (2003): 39-78.

Tovar Pinzón, Hermes. Convocatoria al poder del Número. Bogotá: Archivo General de la Nación, 1994. 